\title{
Erratum to: Safety of Non-anesthesia Provider-Administered Propofol (NAAP) Sedation in Advanced Gastrointestinal Endoscopic Procedures: Comparative Meta-Analysis of Pooled Results
}

\author{
Basavana Gouda Goudra ${ }^{1}$ Preet Mohinder Singh ${ }^{2}$ Gowri Gouda ${ }^{3}$. \\ Anuradha Borle $^{2} \cdot$ Divakara Gouda $^{4} \cdot$ Amulya Dravida $^{1} \cdot$ Vinay Chandrasekhara $^{5}$
}

Published online: 22 March 2015

(C) Springer Science+Business Media New York 2015

\section{Erratum to: Dig Dis Sci}

DOI 10.1007/s10620-015-3608-x

The original version of this article unfortunately contained an error in the coauthor's surname. The name should be Vinay Chandrasekhara, but was submitted and published as Vinay Chandrashakhara.

The online version of the original article can be found under doi:10.1007/s10620-015-3608-x.

Basavana Gouda Goudra goudrab@uphs.upenn.edu;

Basavana.Goudra@uphs.upenn.edu

Preet Mohinder Singh

Preetrajpal@gmail.com

Gowri Gouda

gowri_gouda@yahoo.com

Anuradha Borle

Andromeda85@gmail.com

Divakara Gouda

dg2488@nyu.edu

Amulya Dravida

Amulya.Dravida@gmail.com
Vinay Chandrasekhara

vinay.chandrasekhara@uphs.upenn.edu

1 Department of Anesthesia, Hospital of the University of Pennsylvania, Philadelphia, PA, USA

2 Department of Anesthesia, All India Institute of Medical Sciences, New Delhi, India

3 Drexel University, Philadelphia, PA 19104, USA

4 New York University, New York, NY 110003, USA

5 Department of Medicine, Hospital of the University of Pennsylvania, Philadelphia, PA, USA 